\title{
INCIDENCIA DE LA MODIFICACIÓN DE LA LEGISLACIÓN DE COSTAS EN LA PROTECCIÓN DEL LITORAL ALICANTINO
}

\author{
Ascensión Padilla Blanco y Ma . Paz Such Climent \\ Departamento de Análisis Geográfico Regional y Geografía Física \\ Instituto Interuniversitario de Geografía \\ Universidad de Alicante
}

\section{RESUMEN}

El presente trabajo incluye un análisis preliminar sobre la incidencia que tendrá la aplicación de la Ley $2 / 2013$, de 29 de mayo, de protección y uso sostenible del litoral y de modificación de la Ley 22/1988, de 28 de julio, de Costas, en el litoral alicantino, con el fin de poder evaluar a mayor escala en posteriores investigaciones cómo afectará a un medio natural de gran valor y riqueza (litológica, geológica, geomorfológica, biodiversidad). Para ello, por una parte se exponen de manera crítica los cambios efectuados en la legislación de costas sobre la conservación y, por otro, se destacan los elementos del medio físico que deben de ser urgentemente protegidos por su carácter de singularidad/ rareza/endemicidad o grado de amenaza/vulnerabilidad/fragilidad. Del análisis realizado, se evidencian los previsibles efectos negativos que la modificación de la legislación de costas tendrá en la conservación del medio litoral, lo que justifica la urgente necesidad de reforzar su protección, así como el interés en desarrollar y aprobar instrumentos de ordenación específicos e, incluso, plantear una modificación de la citada ley.

Palabras clave: Ley 2/2013, litoral alicantino, dominio público marítimo-terrestre, patrimonio natural, biodiversidad, protección.

\section{ABSTRACT}

Incidence of amending legislation in protecting the coasts (Alicante coastal environment)

This paper includes a preliminary analysis of the impact that implementation of Ley 2/2013, de 29 de mayo, de protección y uso sostenible del litoral y de modificación de la Ley 22/1988, de 28 de julio, de Costas, in the Alicante coast, in order to evaluate a larger 
scale in future research how it will affect the natural environment of great value and wealth (lithological, geological, geomorphological, biodiversity). To do this, on the one hand exposed critically changes to legislation on the conservation costs and on the other, it highlights the elements of the physical environment that must be urgently protected by their character of uniqueness / rarity / endemism or degree of threat / vulnerability / fragility. From the analysis carried out, foreseeable negative effects that changing the legislation will have on coastal conservation and environment are evident, which justifies the urgent need to improve their protection, as well as interest in developing and approving specific management instruments and even raise a modification of the Ley 2/2013.

Keywords: Ley 2/2013, Alicante coast, maritime-terrestrial public domain, natural heritage, biodiversity, protection.

\section{AlgunAs NOTAS PREVIAS EN TORNO A LA IMPORTANCIA DEL ESPACIO LITORAL}

Aunque los vocablos costa y litoral, se utilizan como sinónimos ${ }^{1} \mathrm{y}$, por tanto, se suelen utilizar indistintamente en la lengua castellana para hacer referencia a la orilla del mar y tierra que está cerca de ella, acepción que también adopta la actual legislación en materia de costas, desde el punto de vista geográfico sus límites se extienden mucho más hacia el interior tanto de la tierra como del mar. Sobre este particular, el profesor Barragán (2004) señala cómo en los textos legales «costa» se vincula a la franja relativamente estrecha situada a un lado y otro del contacto tierra-mar, mientras que litoral se asocia a superficies más amplias, sobre todo en dirección continental. Además, los límites de las áreas litorales pueden variar según los criterios y objetivos que se propongan para llevar a cabo su ordenación y gestión (UNEP, 1994), a lo que se añade que la zona costera, por su propia definición o naturaleza, se haya en permanente cambio y sus recursos en un equilibrio dinámico. De ahí la definición de área litoral propuesta por el citado autor como «franja de anchura variable resultante del contacto interactivo entre la naturaleza y las actividades humanas que se desarrollan en ámbitos que comparten la existencia o la influencia del mar», por lo que comprende tres subáreas bien diferenciadas físicamente: marítima, terrestre y marítimo-terrestre (Barragán, 2004:27).

Tomando como referencia dicha definición, se comprende mejor la dificultad o complejidad que esta realidad geográfica puede entrañar para el legislador a la hora de encajar el medio litoral en las definiciones legales y demás

1. Real Academia Española. (2001). Diccionario de la lengua española (22. a ed.). Consultado en http://www.rae.es/rae.html 
instrumentos jurídico-administrativos previstos para su ordenación y planificación. Por supuesto, esto también afecta al Dominio Público Marítimo-Terrestre (DPMT), al que se hace referencia en el presente artículo, a la hora de fijar su anchura y los límites de los elementos que lo constituyen.

Por otra parte, según la Evaluación de los Ecosistemas del Milenio de España (2011), los litorales se encuentran entre los más productivos pero también más amenazados (Barragán y Chica, 2013) y, en especial, se advierte de la importancia de los servicios ambientales que proporcionan y de su dependencia del buen estado de conservación que, sobre todo, afecta a aquellos a los que se les reconoce un papel fundamental en el mantenimiento de la vida en el planeta, es decir, los servicios de regulación en beneficio de los servicios productivos debido a la intensiva explotación de que son objeto. Así, por ejemplo, se relaciona el intenso proceso de concentración de la población y las actividades económicas en el espacio litoral con el estado de deterioro actual de los ecosistemas que alberga, significándose la pérdida del $59 \%$ de la superficie de los humedales costeros, la situación en mal estado del $80 \%$ de los sistemas dunares, la alteración del $70 \%$ de las lagunas costeras y el elevado porcentaje del litoral en regresión, a lo que también habría que añadir la pérdida de biodiversidad genética y a nivel de especies que conllevan todos estos problemas.

A la vista de esta situación, lo que sí ha de quedar claro es tanto la necesidad de reforzar la protección del sistema litoral como de abordar la ordenación de las áreas litorales con carácter integrado y que el éxito de las medidas y acciones que se puedan proponer dependerá en buena medida de que su delimitación se ajuste a la vez a criterios de índole físico-natural y ecológico como funcional, es decir, habrá de contar con factores de distinta índole (físico-ecológico, socioeconómico, administrativo, histórico-cultural, paisajístico, etc.), en tanto en cuanto su vocación como espacio geográfico.

El requerimiento de llevar a cabo una planificación y ordenación integrada del litoral (PGIZC) responde a la labor de impulso desempeñada por diferentes organismos internacionales (Consejo de Europa, OCDE, ONU, etc.) en los años setenta con el propósito de atender de forma efectiva a la singularidad y fragilidad de las zonas costeras, así como a la problemática que soportan como consecuencia de la presión de diferentes actividades. En ese contexto, la Recomendación 2002/413/CE del Parlamento Europeo y del Consejo de 30 de mayo de 2002, sobre la aplicación de la gestión integrada de las zonas costeras en Europa ${ }^{2}$, la define como un proceso dinámico, continuo e interactivo destinado a promover la gestión sostenible de las zonas costeras. 
Precisamente con el propósito de favorecer su implementación y considerando la premisa de planificar en profundidad espacial y sectorialmente, el Programa de Medio Ambiente de las Naciones Unidas (PNUMA, 1994) propuso una zonificación de las áreas litorales en sentido transversal a la línea de costa, en la que se diferenciaban las siguientes zonas: aguas oceánicas, aguas litorales, espacio intermareal, borde costero, frente litoral, tierras litorales y tierras continentales. No obstante, cabe señalar que en este esquema el borde costero (coastline) es más exactamente la línea de contacto entre el mar y la tierra que viene marcada por la máxima influencia de la acción mareal tierra adentro -pleamar máxima viva equinoccial-, mientras que el frente litoral/costero, según la fuente de referencia, se extendería desde la anterior hacía el interior con una anchura que raramente supera los $1.000 \mathrm{~m}$ y estaría reservada o relacionada con el uso público y la protección de hábitats sensibles. Asimismo, excepto las zonas citadas en primer y último lugar, las restantes constituyen la costa, aunque las actividades desarrolladas en aquellas pueden influir en ella y, lógicamente, también han de tenerse en cuenta a efectos de su planificación y gestión. De hecho, aunque la delimitación de carácter geográfico propuesta por el PNUMA reviste gran interés a la hora de llevar a cabo una protección y gestión eficaces, no hay que olvidar la importancia de abordar el tratamiento del litoral como un sistema en su conjunto que abarque los tres ámbitos que lo integran -marino, terrestre e intermareal-.

VALORACIÓN DE LOS ÚLTIMOS CAMBIOS EN LA LEGISLACIÓN DE COSTAS RESPECTO DE LA PROTECCIÓN Y RECUPERACIÓN DEL DOMINIO PÚBLICO MARÍTIMOTERRESTRE

\section{La ley 22/1988, de 28 de julio, de Costas: expectativas frustradas}

La Ley 22/1988, de 28 de julio, de Costas (LC), materializa o da cumplimiento del mandato constitucional contenido en el artículo 132.2 de la Carta Magna, en el que se declaran como bienes de dominio público estatal los que determine la Ley y, en todo caso, la zona marítimo-terrestre, las playas, el mar territorial y los recursos naturales de la zona económica y la plataforma continental.

En principio, el texto de esta ley, conviene aclarar, si se toma en consideración lo recogido en su exposición de motivos, se refiere de forma indistinta a costa y litoral, es decir, parece no distinguir entre ambos términos en lo que se refiere a su significado geográfico $\mathrm{y}$, además, según dicho preámbulo, su finalidad, al amparado del precepto constitucional citado más arriba, es dar solución a los problemas derivados de la degradación, destrucción y privatización del litoral, ante la insuficiencia y carácter fragmentario de la legislación hasta ese momento vigente. En particular entre los fallos de esta última se destacan, entre otros, la incompleta definición de zona marítimo-terrestre y de playa, que 
no llega a cubrir la realidad natural, la prevalencia de la posesión particular amparada por el Registro de la Propiedad y adquisición privada del dominio público, las servidumbres obsoletas e insuficientes, la ausencia total de medidas de protección en territorio colindante, la usucapión veintenal como título legitimador del uso y la generalización de las concesiones, con lo que ello supone de ampliación de los derechos de sus titulares sobre el dominio público.

Asimismo, se indica que la citada ley, referida a la gestión y conservación del patrimonio natural de ese ámbito geográfico, desarrolla el principio contenido en el artículo 45 del texto constitucional y asume los criterios contenidos en la Recomendación 29/1973 del Consejo de Europa, sobre protección de zonas costeras, en la Carta Europea del Litoral de 1981 de la Comunidad Económica Europea y en otros planes y programas afines. En concreto, la citada Carta Europea del Litoral, a fin de asegurar la protección de las zonas costeras, incluye entre sus recomendaciones, organizar la ordenación en profundidad de la zona litoral, hacia la tierra y hacia el mar, luchar contra la privatización del litoral asegurando el libre acceso del público a la costa, control público del suelo, implementar un plan de gestión del espacio litoral, prohibir las intervenciones humanas susceptibles de provocar riesgos (diques, espigones, etc.), elaborar estudios de impacto ambiental, protección reforzada en lugares excepcionales para impedir su urbanización, etc.

Ahora bien, aunque en ocasiones el legislador se refiera indistintamente a la costa o al litoral y asuma las recomendaciones acerca de la ordenación y gestión de las zonas costeras hechas hasta entonces desde las instituciones europeas, queda claro que el ámbito de actuación de la ley se limita tan sólo, tal como su título indica, a un espacio más restringido, a la franja costera que queda más directamente sometida a la interacción entre el mar y la tierra. En concreto, la ley atiende al DPMT, según su definición contenida en el precepto constitucional, pero además su regulación se extiende tan sólo a la parte más terrestre del dominio y ceñida a una estrecha franja donde se ponen en contacto la tierra y el mar. Es cierto que este hecho suscitó no pocas suspicacias en torno al nombre de la ley y se esgrimió que más bien debería de haberse llamado ley del dominio público marítimo-terrestre y no de costas y, esto, a pesar de haber ampliado sus límites con el reconocimiento de nuevos elementos según una concepción de la ribera del mar más acorde con sus características físicas y, también, favorecido su extensión a tenor de la propia prerrogativa legal contenida en el artículo 132.2 $\mathrm{CE}^{3}$. En particular, por lo que se refiere a los dos espacios constitutivos

3. El art. 132.2. de la Constitución Española: «Son bienes de dominio público estatal los que determine la ley y, en todo caso, la zona marítimo-terrestre, las playas, el mar territorial y los recursos naturales de la zona económica y la plataforma continental» (Constitución Española, 1978). 
de la ribera del mar y de las rías, si se compara el texto legal aprobado en 1988 antes de su modificación llevada a cabo en mayo de 2013, con la Ley de Puertos de 1928 y la Ley 28/1969, de Costas, para la primera el límite interior de la zona marítimo-terrestre viene determinado por el alcance de las olas en los mayores temporales conocidos mientras que en la norma precedente se remitía a los temporales ordinarios y, además, incluye dentro de la misma los terrenos bajos inundables ${ }^{4}$. En concreto, según su artículo tercero, dentro de la zona marítimoterrestre «se consideran incluidas en esta zona las marismas, albuferas, marjales, esteros y, en general, los terrenos bajos que se inundan como consecuencia del flujo y reflujo de las mareas, de las olas o de la filtración del agua del mar» (art. 3.1.a LC), lo que se completa con la también clasificación demanial de los terrenos naturalmente inundables, cuya inundación por efecto de las mareas haya sido impedida por medios artificiales, así como aquellos otros que por causas artificiales pasen a ser inundados por las aguas del mar siempre que su cota sea menor que la de la mayor pleamar (art.6.2. RLC). Asimismo, a esta ampliación de la zona marítimo-terrestre, se añade la de las playas, ya que no solo comprende la playa seca que quedaba excluida del concepto en la Ley de Puertos, sino también las dunas a las que no se hacía mención en la Ley de 1969. En particular en esta última se definían las playas como «arenales o pedregales en superficie casi plana, con vegetación nula, o escasa y característica», mientras que en el texto de 1988 se describen como «zonas de depósito de materiales sueltos tales como arenas, gravas y guijarros, incluyendo escarpes, bermas y dunas, tengan o no vegetación, formadas por la acción del mar o del viento marino, u otras causas naturales o artificiales» (art. 3.1.b LC), definición o concepto mucho más acorde con criterios geomorfológicos, topoecológicos y fisiográficos que además respeta la asociación natural entre playa y duna. Por último, la Ley 22/1988, de Costas, a diferencia de las anteriores, declara la pertenencia al DPMT de los acantilados sensiblemente verticales, que estén en contacto con el mar o con espacios de dominio público hasta su coronación (art. 4. 4. LC).

Por tanto, aunque la consideración relativa a su título no carezca de fundamento, esta ley supuso un avance con respecto a las precedentes a la hora de abarcar dentro de los límites del DPMT los bienes que lo integran conforme a la configuración de las zonas costeras y sus elementos físicos constitutivos, respetando mejor las diferentes unidades ambientales características. Pero, además, como en el propio preámbulo de la ley se reconoce, se establecen mecanismos

4. Véase, por ejemplo, un estudio comparativo más exhaustivo en Menéndez Reixach, A. (1988): «La nueva Ley de Costas: el Dominio Público como régimen jurídico de protección especial», Estudios Regionales, n. ${ }^{\circ} 22$ : 113-123 o, también, Moreno Cánoves, A. (1990): Régimen jurídico del litoral. Madrid: Tecnos. 
que favorecen la incorporación de terrenos al DPMT según lo establecido en su artículo cuarto respecto, entre otros elementos, a los terrenos ganados al mar como consecuencia de obras, los desecados en la ribera del mar (art. 4.2. LC) y los terrenos incorporados por los concesionarios para completar la superficie de la concesión (art. 4.7.LC).

Por otra parte, la protección y salvaguarda del DPMT también queda garantizada por las limitaciones de la propiedad sobre los terrenos colindantes con la ribera del mar a través del establecimiento de las servidumbres legales, incluyendo aparte de las de tránsito y de acceso al mar, la servidumbre de protección, que se hace recaer sobre una zona de 100 metros desde el límite interior de la ribera del mar, en sustitución de la vieja servidumbre de salvamento que se contaba sobre veinte metros tierra adentro desde el límite interior de la zona marítimo-terrestre. Además en ella, junto con otros usos se prohíben, excepto por razones de utilidad pública, las edificaciones destinadas a residencia o habitación, mientras que en la anterior sí contemplaba la posibilidad de edificar con la autorización previa pertinente. Además, la función de protección de estas servidumbres se completa con la zona de influencia, que ha de tener como mínimo 500 metros a contar desde el límite interior de la ribera del mar y en la cual los instrumentos de ordenación territorial y urbanística han de evitar la formación de pantallas arquitectónicas o acumulación de volúmenes y, en todo caso, que su densidad edificatoria supere la media del suelo urbanizable programado apto para urbanizar, lo que en principio cabe interpretar como un intento de llevar a cabo una ordenación en profundidad. Sin embargo, a pesar de las expectativas suscitadas, en la práctica estas medidas han tenido un efecto bastante menor del esperado por las razones que sucintamente se comentan más adelante.

Ahora bien, si las insuficiencias atribuidas a la Ley de Costas en la protección y gestión del litoral han sido en buena medida cubiertas en la actualidad, al menos por lo que atañe al medio marino, mediante la transposición al ordenamiento jurídico español de la Directiva Marco de Aguas (La Directiva 2000/60/ $\mathrm{CE}$ por la que se establece un marco comunitario de actuación en el ámbito de la política de aguas) y la Directiva Marco sobre la Estrategia Marina (la Directiva 2008/56/CE del Parlamento Europeo y del Consejo, de 17 de junio de 2008, por la que se establece un marco de acción comunitaria para la política del medio marino), no ha pasado igual en el sentido opuesto, es decir, en su desplazamiento hacia tierra por diversas razones.

En primer lugar y, a pesar de su talante protector, los limitados efectos de la Ley 22/1988, de Costas se atribuyen a su limitado ámbito de actuación (DPMT) y a la dificultad añadida de su materialización a través de los instrumentos previstos a tal fin en su texto, es decir, el deslinde y las concesiones. Respecto a su zona de afección, el DPMT prácticamente se ha limitado a las zonas emergidas más inmediatas a la orilla del mar (Torres, 2014), a lo que también se añade la 
falta de una mejor definición de sus elementos constitutivos (García, 2004). Así, por ejemplo, Torres (2014) llama la atención sobre conceptos sin definir y otros mal definidos, lo que ha dificultado la identificación y delimitación de los bienes por parte de la Administración al carecer en bastantes ocasiones de actos probatorios suficientes, caso bastante claro cuando se hace referencia a los mayores temporales conocidos para la delimitación de la ribera del mar (art. 3.1. a LC). Como se verá la Ley $2 / 2013$, de 29 de diciembre, de protección y uso sostenible del litoral y de modificación de la Ley 22/1988, de 28 de julio, de Costas (LCM) ha intentado reparar estas carencias aunque sin mucha fortuna.

A la par, la incidencia de la Ley 22/1988, de Costas ha resultado bastante menor de lo que en principio se esperaba a su entrada en vigor por el importante proceso de ocupación y edificación en los espacios aledaños al mar e, incluso, ganados al mismo. Esta importante privatización y desnaturalización de los espacios de DPMT a la entrada en vigor de la Ley 22/1988, aparte de evidenciar su carácter tardío, ha complicado y retrasado el procedimiento administrativo de tramitación de los deslindes por el elevado número de particulares afectados a los que se ha de notificar y que además aportan sus correspondientes escrituras de propiedad, lo que ha deparado el inicio de litigios en el Tribunal Supremo y en la Audiencia Nacional. A esta dificultad administrativa y la problemática social asociada, se añade el tiempo que requiere, tal como se especifica en el artículo 93 del Reglamento vigente, la elaboración de los diversos estudios técnicos necesarios por su complejidad y los trabajos de campo asociados en los que, tal como se recoge en las instrucciones técnicas para su realización, se deber tener en cuenta la realidad de la costa a lo largo del tiempo, y situación respecto a la legislación vigente en cada momento. Al respecto, cabe tan sólo añadir, a modo de justificación, la ya comentada dificultad que la propia naturaleza del litoral entraña en cuanto a la indeterminación de sus límites físicos -anchura variable-, el intercambio constante de flujos, áridos y energía entre sus elementos, y el continuo movimiento o cambio al que se hayan sometidos y que se traduce en un equilibrio dinámico que no sólo dificulta la definición legal, sino también la delimitación física de unos bienes, cuyo deslinde, sin embargo, reviste una gran trascendencia para su gestión.

Por ello, aunque en la ley no se establecía plazo alguno para aprobar el deslinde del litoral español y si bien, dado su interés, la Dirección General de Costas estableció un Plan de Deslindes (2004-2011) para su finalización, sólo a finales de 2013 se había completado prácticamente en su totalidad y, se había deslindado exactamente el 95,35\% del mismo. Por otra parte, a través de la determinación física e, incluso, aprobación del deslinde como acto administrativo, no siempre ha sido posible hacer efectiva la posesión y la titularidad dominical a favor del Estado, ya que las ocupaciones amparadas en títulos de 
propiedad se han transformado en concesiones, con lo que no es posible tampoco a corto plazo recuperar el dominio público para el uso público.

Además, sobre el DPMT recaen competencias de las tres administraciones territoriales y, aunque en algunas Comunidades Autónomas se puedan reseñar actuaciones e iniciativas de interés encaminadas a la gestión del litoral e, incluso, organismos de coordinación ${ }^{5}$, en la Comunidad Valenciana los instrumentos previstos para su ordenación y gestión no se han llegado a desarrollar, ni siquiera aprobar, como ha ocurrido con el Plan de Acción Territorial del Litoral, que ya estaba contemplado en la primera ley de ordenación del territorio aprobada por el Gobierno valenciano, así como en la siguiente, es decir, la Ley 4/2004, de Ordenación del Territorio y Protección del Paisaje ${ }^{6}$ y en la Estrategia Territorial (Decreto 1/2011, de 13 de enero) desarrollada a su amparo. En este contexto, aunque esta última dispone en su título sexto dedicado al Litoral una serie de principios directores de planificación y gestión de aplicación directa con carácter general para las administraciones públicas, no se puede olvidar que el Plan de Acción Territorial es el instrumento realmente operativo a la hora de materializar una estrategia de ordenación y gestión del litoral trasladando sobre el terreno fórmulas y actuaciones concretas de coordinación supramunicipal y definiendo los elementos de la llamada infraestructura verde del litoral que, según la Estrategia Territorial, ha de incluir todos los espacios de valor ambiental, cultural y paisajístico situados dentro de la franja de $1.000 \mathrm{~m}$ desde la línea interior de la ribera del mar, así como el sistema de gobernanza a aplicar.

La Ley 2/2013, de 29 de mayo, de protección y uso sostenible del litoral y de modificación de la Ley 22/1988, de 28 de julio, de Costas: un paso atrás para su conservación

Si la Ley 22/1988, al margen de su repercusión, se valió el reconocimiento de ser una ley protectora, su modificación a través de la Ley 2/2013, a pesar de su nombre y lo expuesto en su preámbulo, no ha redundado en una mayor protección del litoral y, en particular, del DPMT sino operado en el sentido contrario, es decir, en su detrimento, lo que se ha interpretado como un giro hacia un planteamiento más economicista (Arana y Navarro, 2013; Menéndez, 2014; y García y Sanz, 2014).

Tal como se recoge en su preámbulo, la Ley 2/2013 tiene como objetivos garantizar la protección del litoral, a la par que proporcionar seguridad jurídica frente a las situaciones derivadas de la aplicación de la Ley 22/1988, de Costas

5. Véase http://hum117.uca.es/grupogial/paginas/proyectos/REGIAL/dafo

6. Esta ley fue derogada por la Ley 5/2014, de 25 de julio, de Ordenación del Territorio, Urbanismo y Paisaje de la Comunitat Valenciana (DOGV n. ${ }^{\circ} 7329$, de 31 de julio de 2014). 
en relación a ciertas ocupaciones del DPMT, introduciendo al efecto cambios importantes en la misma.

En particular, interesa sobre todo destacar los cambios introducidos en la definición del DPMT por lo que atañe a sus elementos constitutivos y, en especial, a aquellos comprendidos en la ribera del mar y las rías. En concreto, dentro de esta última, el límite interior de la zona marítimo-terrestre queda determinado por el alcance de las olas en los mayores temporales conocidos de acuerdo con los criterios técnicos contenidos en el artículo cuarto del nuevo Reglamento General de Costas (NRC), en el cual se establece que dicho límite habrá de ser alcanzado al menos en cinco ocasiones en un periodo de cinco años salvo casos excepcionales, mientras que en el Reglamento anterior se remitía a «las referencias comprobadas de que se disponga» (art. 4. a RC). Ahora bien, conviene aclarar que si bien el nuevo Reglamento remite para la determinación del alcance de un temporal a las máximas olas registradas con boyas o satélites o a su cálculo a través de datos oceanográficos o meteorológicos, independientemente de los modelos utilizados para calcular los parámetros del oleaje, su efecto en la costa estará condicionado por la dirección y fuerza del viento, las características de los fondos antelitorales, como del tipo de costa y línea de costa.

A lo anterior hay que añadir también que las boyas no miden las olas aisladamente, una a una, sino que se registran durante un cierto periodo de tiempo, más o menos cada media hora, debido a que el oleaje es un fenómeno irregular por lo que hay olas de distintas alturas que se suceden una tras otra. Así pues, con la información que suministran lo que se calcula es la altura media, lo que se conoce como altura significante (Hs), es decir, la media del tercio de olas más altas ${ }^{7}$.

Por otra parte, sujetar el dato del alcance de los mayores temporales a la repetición del fenómeno de la forma indicada, hace mucho más difícil su determinación y, desde luego, excluye la incidencia de acontecimientos excepcionales o grandes temporales que pueden afectar a la costa pero con periodos de retorno o intervalos de tiempo mayores.

Asimismo, a propósito de esto último y teniendo en cuenta que entre los fines de la intervención de la Administración en el dominio público, dentro de su reciente modificación, se ha añadido también la adaptación al cambio climático (art. 2. a LCM), llama la atención que no se haya tenido en cuenta que entre sus efectos se prevé una acentuación de ciertos elementos como el oleaje o, por ejemplo, los resultados de un estudio elaborado por científicos de la Universidad de Cantabria, fruto de un convenio de colaboración con la Oficina Española de Cambio Climático -integrada en el Ministerio de Medio Ambiente (MAGRAMA)-, referido al impacto en la costa española por efecto del cambio

7. http://www.puertos.es/es-es/Paginas/FAQ.aspx\#faq6 
climático, en el que se estima una subida del nivel del mar para 2050 que puede oscilar entre los 12 ó $15 \mathrm{~cm}$ y los $30 \mathrm{~cm}$, según los diferentes sectores costeros, a tenor de una variación del nivel medio del mar de 2,5-3,0 milímetros/año y que provocaría el consiguiente retroceso de la línea de costa (Losada, 2008).

Al mismo tiempo, según el artículo tercero de la Ley $2 / 2013$, quedan excluidos del DPMT, los terrenos que sean inundados artificial y controladamente, como consecuencia de obras o instalaciones realizadas al efecto, siempre que antes de la inundación no fueran de $\mathrm{DPMT}^{8}$, cambiando por tanto el criterio anterior de la Ley 22/1988, según el cual los terrenos invadidos por el mar que pasasen a formar parte de su lecho por cualquier causa (art. 4.3.LC) sí se incluían en el dominio público mientras que su cota no fuera superior a la de la mayor pleamar (art. 6.2. RLC). Además, a esta modificación se añade que los terrenos invadidos por el mar por otras causas distintas a las señaladas, sólo tendrán esa consideración si son navegables (art 3. 4. LCM).

Por otra parte, en el caso de la playa, las dunas se incluirán sólo hasta el límite que resulte necesario para garantizar la estabilidad de la playa y la defensa de la costa y, a estos efectos, según el nuevo Reglamento, tal función la cumplen las dunas que están en desarrollo, desplazamiento o evolución debida a la acción del mar o del viento marino, las dunas primarias y las dunas secundarias hasta su borde interior pero se entiende que no son necesarias las dunas relictas y las dunas estabilizadas, salvo en aquellos casos excepcionales (art.4.d NRC).

Así pues, si se atiende al artículo cuarto del nuevo Reglamento, que recoge los criterios técnicos para la determinación de la zona marítimo-terrestre y de la playa, se entiende por duna en desarrollo o embrionaria aquella con muy pequeña cobertura vegetal y por duna en desplazamiento o evolución aquella otra poco o nada vegetada, formada por arena suelta, que avanza desde la costa hacia tierra adentro por la acción del viento marino, mientras que duna primaria sería aquella con cobertura parcial de vegetación, duna secundaria la no estabilizada o en desplazamiento con cobertura de vegetación herbácea que puede alcanzar hasta el 100\% y/o vegetación leñosa arbustiva o arbórea que puede alcanzar hasta el $75 \%$ de su superficie. Por su parte, la duna estabilizada se define como una duna estable, colonizada por vegetación leñosa arbustiva o arbórea en más del $75 \%$ de superficie y la relicta la formada en otro tiempo geológico que ha que quedado aislada tierra adentro o colgada sobre una costa rocosa, sin vinculación con ninguna playa. Aparte de que esto no siempre es así, la exclusión de las

8. Es más, según el nuevo punto 5 añadido a la Disposición Transitoria 1. a de la Ley de Costas, respecto a ocupaciones en la zona marítima o playa ya deslindados o no cuyos titulares estén inscritos en el Registro de la Propiedad y amparados por el artículo 34 de la Ley Hipotecaria, si se trata de terrenos inundados artificial y controladamente como consecuencia de obras o instalaciones realizadas al efecto que estén destinadas a actividades de cultivo marino o salinas, se excluirán del DPMT aun cuando sean naturalmente inundables. 
Figura 1: Delimitación de los Bienes de Dominio Público Marítimo-Terrestre y servidumbres legales

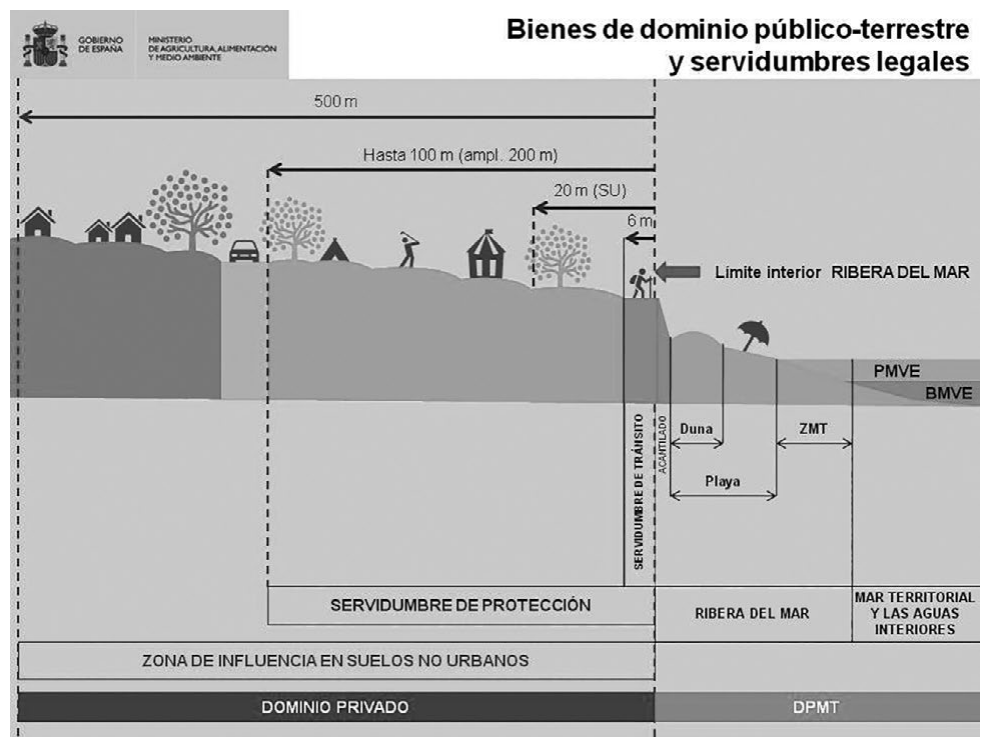

Fuente: http://www.magrama.gob.es/es/

dunas estabilizadas no queda suficientemente justificada porque forman parte del sistema litoral y también ejercen una importante labor defensiva de la costa nada despreciable, sobre todo, en el caso de temporales excepcionales como los que se han registrado en algunas ocasiones en distintos puntos del $\operatorname{litoral}^{9} \mathrm{y}$, además, respecto a las previsiones de los efectos de elevación del nivel marino, habría sido más coherente adoptar criterios más conservacionistas a la vista de la acentuación del riesgo en tramos de costa donde las primeras alineaciones dunares han sido ocupados por la urbanización, caso, por ejemplo, de algunos puntos del litoral alicantino.

A esta indefensión de parte del sistema dunar, que habría de englobarse en su conjunto para su mejor gestión, se une la posibilidad de ocupar la superficie de las playas para la construcción de obras de defensa en el caso de terrenos amenazados por la invasión del mar o de sus arenas, por causas naturales o artificiales, siempre que no perjudiquen al DPMT (art. 6 LCM), posibilidad que en la LC 1988 no se contemplaba.

Asimismo, la nueva redacción del artículo 33 introduce otro de los cambios referidos a las playas y que afecta a su régimen de ocupación y uso que, según el

9. Véanse, por ejemplo, los siguientes trabajos: Tros-De-Ilarduya (2005, 2012 y 2013), Yanes Luque, A. y Marzol Jaén, M. ${ }^{a}$ V.(2009), Torres y Olcina (1997) y Torres (2002). 
nuevo punto sexto añadido a dicho artículo, se establecerá reglamentariamente atendiendo a su carácter natural o urbano. Así, mientras que los clasificados como naturales se dice que se someterán a un alto grado de protección, los urbanos se abren a la posibilidad de acoger la celebración de «eventos de interés general con repercusión turística» que cumplan con los necesarios requisitos para garantizar su mantenimiento y con el levantamiento de las instalaciones tras su finalización. Además, esta autorización, según el artículo 66 del NRC, también podrá aplicarse en DPMT que no tenga la condición de playa siempre que se prevea una afección a la misma.

A la vista de estos cambios cabe comentar en primer lugar que ante todo con esta permisividad se está vulnerando el artículo 31.1 LC, según el cual la utilización del DPMT y, en todo caso, del mar y su ribera será libre, pública y gratuita para los usos comunes y acordes con su naturaleza, que no requieran obras e instalaciones de ningún tipo y que se realicen de acuerdo con las leyes y reglamentos, ya que en la definición de «eventos de interés general con repercusión turística» cabe una amplia posibilidad de actividades, entre las que se encuentran los grandes festivales musicales tan de moda de un tiempo a esta parte que ocupan durante varios días la playa y, además, generan bastantes desperfectos y acumulación de residuos, lo que lógicamente puede tener efectos muy perjudiciales en la vegetación propia de estos ecosistemas. En segundo lugar, de acuerdo con el artículo 32.1. LC, que no ha sido objeto de modificación, únicamente se podrá permitir la ocupación del DPMT para aquellas actividades o instalaciones que por su naturaleza no pudieran tener otra ubicación, lo cual desde luego no se cumple en este caso.

Pero no sólo las playas ven incrementada su presión de uso de una manera innecesaria por las modificaciones comentadas anteriores, sino que también el artículo 69 del NRC, al regular la ocupación de los tramos urbanos de las playas, dispone que el MAGRAMA puede dar permiso para que las edificaciones de servicio de playas se ubiquen en el límite interior de la playa incluso a escasos $70 \mathrm{~m}$ desde la línea de pleamar, siempre que no se perjudique el DPMT, cuando el artículo 33.3. de la LC dispone que se ubicarán, preferentemente, fuera de las mismas y el anterior Reglamento, precisaba que cuando esto no fuera posible, se podrían situar adosadas a su límite interior. Además, respecto a las instalaciones fijas destinadas a establecimientos expendedores de comidas y bebidas, establece una ocupación máxima que tanto en lo que se refiere a edificación cerrada como abierta aumenta su superficie con respecto a la establecida en el Reglamento de Costas derogado y, además, deja abierta la posibilidad de su ampliación en casos excepcionales debidamente justificados pero sin especificarlos dejando así un margen de discrecionalidad importante. Por otra parte, en los tramos clasificados como naturales, lejos de lo que sería deseable, también se admite, aunque con unos parámetros de ocupación menores, este último tipo 
de uso, lejos, por tanto, de lo que cabría esperar de acuerdo con el elevado nivel de protección que el artículo 33.6 LCM les atribuye.

En cuanto a la recuperación y salvaguarda del DPMT para el uso público, dicho objetivo lógicamente queda más bien relegado frente a los derechos de propiedad y el amplio margen temporal previsto en el régimen concesional, que pasa de 30 a 75 años y a cuyos titulares se les permite su transmisión mortis causa e inter vivos. Esta última, prerrogativa introducida en la nueva normativa, previa autorización de la Administración, mientras que para la transmisión mortis causa, ya contemplado en el texto de 1988, se amplía el plazo, que pasa de uno a ser de cuatro años, para que los herederos puedan subrogarse en el título.

Junto a esto último y como consecuencia de la situación heredada al amparo de la legislación aplicable antes de la entrada en vigor de la Ley 22/1988, se mantiene lo dispuesto en la Disposición Transitoria primera, según la cual los titulares de un derecho de propiedad al amparo del art. 34 de la Ley Hipotecaria, pasan a ser concesionarios, al igual que aquellos otros titulares de terrenos inscritos en el Registro de la Propiedad que no hayan podido ser ocupados por la Administración al practicar un deslinde anterior a la entrada en vigor de la Ley de Costas pero eliminando el plazo previsto de un año para su solicitud, lo que también se hace extensivo para quienes con esa misma condición se encuentren en tramos de costa no deslindados o lo estén parcialmente. Pero, además, el artículo segundo de la nueva ley concede una prórroga extraordinaria a las concesiones otorgadas al amparo de la legislación anterior, lo que también se aplica a los titulares de un derecho de ocupación y aprovechamiento del DPMT conforme a la disposición transitoria primera de la Ley de Costas, si bien deberán solicitar la correspondiente concesión antes de que venza el plazo fijado para su extinción, de manera que el plazo de la prórroga se computará desde la fecha de la solicitud, con independencia del plazo que reste de la concesión que se prorroga. Por tanto, a través de este procedimiento, la ocupación y uso privativo del DPMT podrá extenderse a un total de 135 años porque aquellos concesionarios que hayan renovado su título antes de la entrada en vigor de la Ley 2/2013 por treinta años, podrán ampliarla por otros setenta y cinco años.

Aún siendo importantes los cambios introducidos hasta ahora comentados, todavía cabe añadir los efectos que en la privatización del DPMT seguramente tendrán varias de las disposiciones adicionales incluidas en el texto de la Ley 2/2013. Entre ellas se prevén procedimientos especiales de deslinde a la carta, criticándose su carácter arbitrario y abusivo al tratar situaciones idénticas de distinta forma (García, 2014). Así, en ellas, dispone que la Administración General del Estado proceda a la revisión de los deslindes ya ejecutados y que se vean afectados como consecuencia de la aprobación de la Ley 2/2013 (D.A. 2. a), y, a su vez, a tenor de su resultado prevé la devolución del dominio de los terrenos que dejen de formar parte del DPMT a los antiguos propietarios o a sus 
sucesores si en el nuevo deslinde resultan excluidos (D.A. 5. ${ }^{a}$ ) o los reintegros del dominio de los terrenos de las urbanizaciones marítimo-terrestres cuando sus títulos estén inscritos en el Registro de la Propiedad (D.A. 6. ${ }^{a}$ ), a lo que se añade, la posibilidad de desafectar los terrenos situados al interior de los paseos marítimos construidos entre la entrada en vigor de la Ley 22/1988, de Costas y la Ley $2 / 2013$, tras disponerse también que su línea exterior se entenderá como la línea interior de la ribera del mar (D.A. $\left.3{ }^{a}{ }^{a}\right)$, como también la exclusión de un conjunto de núcleos de población recogidos en el anexo (D.A. 7.ª) y, además, el particular deslinde de la isla de Formentera (D.A. 4. ${ }^{a}$ ). En esta última el límite interior de la zona marítimo-terrestre se fija sólo en función de los temporales ordinarios en lugar de a los mayores temporales y sin incluir referencia alguna a marismas, albuferas, marjales, esteros, mientras que para las playas no se considera la existencia de dunas.

Por último, si la ya difícil recuperación del DPMT se ha visto si cabe más comprometida tras la entrada en vigor de la Ley $2 / 2013$, sus consecuencias también se han extendido a las servidumbres legales cuyo efecto en la protección del demanio se reduce, tal como resulta del nuevo apartado tercero del artículo 23 , que reduce a 20 metros la anchura de la servidumbre de protección en los márgenes de los ríos hasta donde sean sensibles las mareas o, también, la operada como consecuencia del nuevo trazado de la línea interior de la ribera del mar de forma coincidente con la línea exterior de los paseos marítimos, así como la posibilidad abierta por la disposición transitoria primera de la Ley 2/2013 respecto a la aplicación de lo previsto en el apartado tercero de la Disposición Transitoria tercera de la Ley 22/1988, para aquellos núcleos o áreas que, a su entrada en vigor, no estuvieran clasificados como suelo urbano pero que, en ese momento, reunieran alguno de sus requisitos, de manera que en ellos también se operará la consiguiente reducción pasando de 100 metros a los 20 metros.

En definitiva, los cambios comentados no se avienen al cometido que, en principio, se atribuía la propia Ley de Costas que no era otro que regular el régimen jurídico del dominio público según los principios de inembargabilidad, inalienabilidad e imprescriptibilidad contemplados en el precepto constitucional, ni tampoco se garantiza el derecho a disfrutar de un medio ambiente adecuado porque no se garantiza la defensa de la integridad del litoral mediante la protección de sus valores y elementos constitutivos ni se atiende a los efectos del cambio climático.

\section{LA RIQUEZA DEL PATRIMONIO NATURAL EN EL LITORAL ALICANTINO}

Es fundamentalmente el factor geomorfológico el que justifica la gran diversidad y el valor del patrimonio natural en el litoral de la provincia de Alicante; es el soporte de las formaciones vegetales y de la fauna que lo colonizan y, 
precisamente, por las particularidades de este medio físico, ha sido objeto de una devastadora e intensa ocupación por el sector terciario y por las actividades turísticas que pueden acabar extinguiendo hábitats naturales de importancia internacional y especies únicas en el planeta (Padilla y Such, 2001).

El elevado valor y, al mismo tiempo, gran fragilidad de esta estrecha franja terrestre y marítima son la causa del también importante número de figuras de protección internacionales, europeas, nacionales y valencianas que recubren y, en muchas ocasiones, se solapan en este territorio; así como del vasto aparato legislativo existente en lo que concierne a la conservación (Morte y Padilla, 1997; Padilla, 2002); aún así insuficiente, debido a la falta de coordinación entre políticas territoriales y ambientales y a la primacía de intereses económicos.

El elevado interés que suscita la protección del litoral alicantino merece el que, más que hablar de medio físico en este apartado, se haya optado por la denominación de patrimonio natural, atendiendo a la definición que como tal se adjudicó en la Convención sobre la protección del patrimonio mundial, cultural y natural ${ }^{10}$, a monumentos naturales, formaciones fisiográficas y geológicas, hábitats de especies amenazadas y a todo lugar o zona natural que tengan un valor universal excepcional desde el punto de vista científico, estético y/o de conservación. A lo largo del desarrollo de este apartado se demostrará y se hará evidente el correcto uso de «patrimonio natural» para referirnos al litoral alicantino.

Por lo tanto, se presenta un tema de investigación muy interesante y de gran envergadura que, en esta ocasión, se aborda desde un punto de vista general y con carácter introductorio y como aproximación a futuros análisis a una escala de más detalle.

\section{El relieve costero, soporte de la riqueza vegetal y animal.}

Son muchas las obras de referencia que han analizado a diferentes escalas el litoral valenciano y sus costas. Nuestra pretensión en este artículo se reduce a justificar su importancia desde el punto geológico, geomorfológico y como medio determinante para la presencia de algunas especies de flora y de fauna de interés.

En primer lugar, es muy importante la diversidad geomorfológica y fisiográfica que, en esta ocasión, la reduciremos a tres tipologías: costas de erosión

10. Convención sobre la protección del patrimonio mundial, cultural y natural, documento de La Conferencia General de la Organización de las Naciones Unidas para la Educación, la Ciencia y la Cultura, en su 17a, reunión celebrada en París del 17 de octubre al 21 de noviembre de 1972. 
(acantilado tipo plunging ${ }^{11}$, plataforma de abrasión y karst litoral), costas de acumulación (playas de arenas, de cantos) y sectores albufereños. Estos últimos se suelen incluir en las costas de acumulación, pero debido a la gran importancia que tienen como hábitat de interés comunitario (Directiva 92/43/CEE) y como espacios con elevada biodiversidad, se ha preferido considerarlos aparte.

A grandes rasgos, se puede hacer una diferenciación entre un norte de la provincia fundamentalmente montañoso que genera una variada costa acantilada donde predominan los procesos erosivos marinos a los subaéreos, y un sur con depresiones que determinan la presencia más abundante de costas de acumulación y de espacios húmedos. Las zonas acantiladas están muy determinadas por el tipo de material dominante y el de estructura; cuanto más blando es éste y menor la pendiente, las plataformas de erosión son más extensas. Por otra parte, la erosión marina aprovecha las líneas de debilidad tectónica y estructural, favoreciendo el retroceso del acantilado. En algunas de estas plataformas nos podemos encontrar un modelado kárstico, pero son procesos que afectan a sectores reducidos y dan lugar a multitud de formas; de ahí que para este trabajo sólo se indiquen aquellas zonas donde hay una mayor representatividad. (Eulalia, 1985).

En resumen, como bien indican Marco, Matarredona y Prieto (2006), la morfología del litoral alicantino se debe fundamentalmente a la tectónica, a los aportes de materiales de origen continental y marino, y a las condiciones atmosféricas durante el pliocuaternario. Es, por tanto, de una gran variedad y riqueza estructural y geomorfológica, destacando algunos sectores que todavía no han sido totalmente transformados o urbanizados y que deberían de ser justificación suficiente para modificar los parámetros de la Ley 2/2013 o de ser protegidos, en caso de que no estén incluidos todavía en alguna figura de protección de la Comunidad Valenciana como Parque Natural, Paraje Natural Municipal o Paisaje Protegido. Por ejemplo, de norte a sur podríamos enumerar en una primera aproximación: la costa acantilada baja con plataforma estrecha en la que se desarrolla modelado kárstico entre Les Bovetes, Les Rotes y Arenetes; así como toda la costa acantilada desde el Cabo de San Antonio hasta el Portet de Moraira, desde la Playa de la Cala (Finestrat) hasta la Playa del Torres (La Vila Joiosa) y desde La Vilajoiosa hasta el Campello; el acantilado bajo con acera litoral del Cap de L'Horta; acantilado tipo plunging de Serra Grossa; Saladar d'Aigua Amarga; acantilado con plataforma litoral en Serra del Carabassí y Serra de Santa Pola, destacando el hito geológico de esta sierra como arrecife fósil; LIC

11. Plunging cliff, término anglosajón que define un acantilado vertical de material resistente generado por accidentes tectónicos, mientras que los procesos marinos y subaéreos tienen un carácter secundario. 
Figura 2. Figuras de protección nacionales en el litoral alicantino

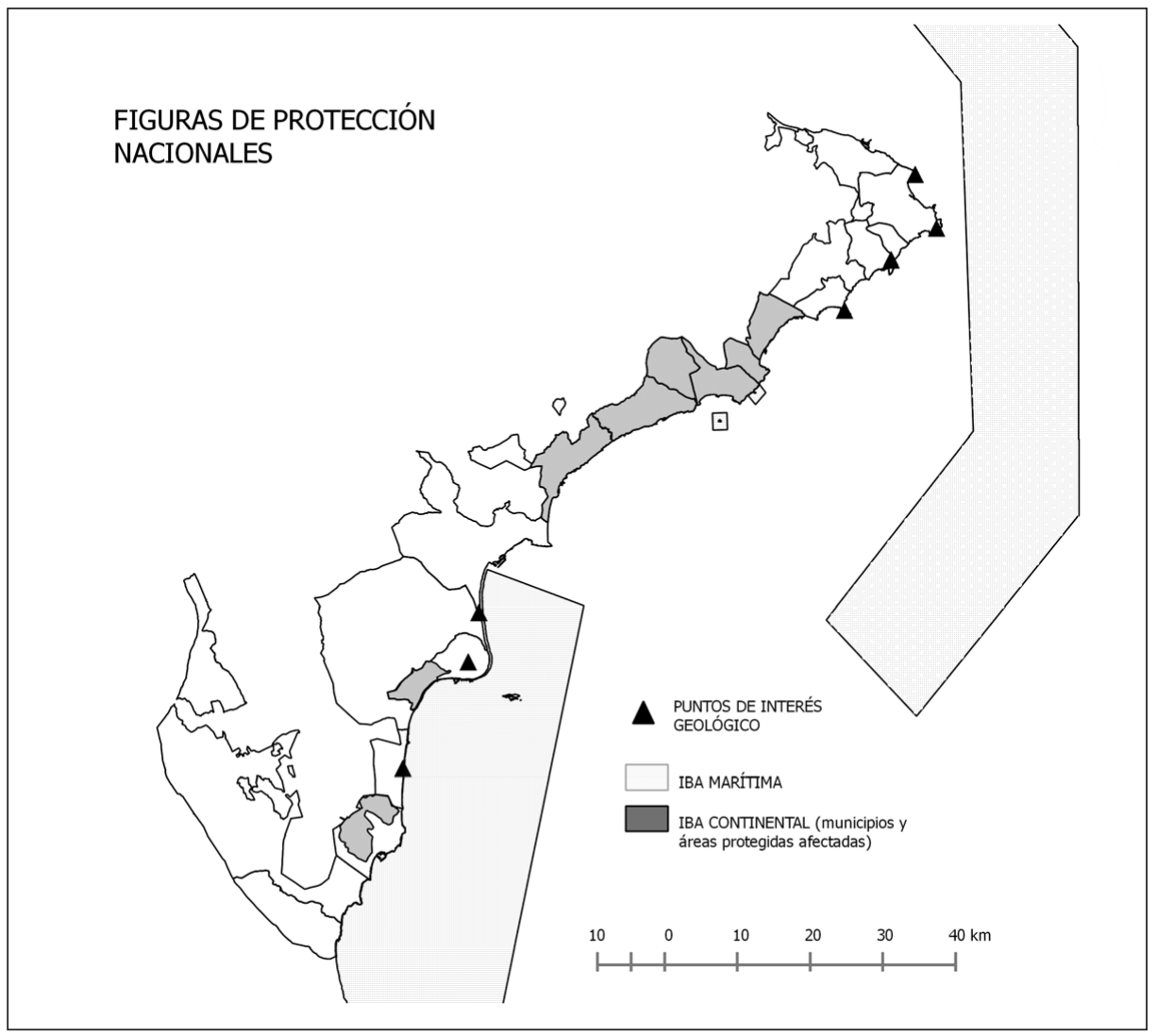

Fte.: MAGRAMA, IGME. Elaboración propia

Dunes de Guardamar; y la sucesión de acantilados y calas desde Punta Prima hasta Cabo Roig.

Es evidente el valioso patrimonio geológico y geomorfológico que encierran nuestras costas y, aunque indirectamente sea reconocido por las distintas figuras de protección junto al resto de elementos del medio natural (paisaje, biodiversidad, flora y fauna de interés), es cierto que la mayoría de las ocasiones queda relegado a un segundo plano. Sólo a través de los «Puntos de Interés Geológico» del Instituto Geológico y Minero de España (IGME-Ministerio de Economía y Competitividad) se reconoce directamente la importancia y el interés de su conservación (Figura 2). En el litoral alicantino son siete los espacios así denominados, ubicados en la plataforma marina del Montgó, rasa marina del cabo de San Antonio, plataforma del cabo de la Nao, Peñón de Ifach y arrecife 
de Santa Pola, como costas de erosión; dunas de Arenales del Sol y cordón de dunas de Guardamar del Segura, como costas de acumulación; y las Salinas de Torrevieja, como espacios húmedos. Algunas de las cavidades existentes en esas costas de erosión están incluidas en el Catálogo Valenciano de Cuevas, lo que no supone en sí ningún tipo de protección, aunque sí un reconocimiento de su valía: Cova Tallada (Cabo de San Antonio) y el grupo de Cova del Llop Marí, Cova del Moraig y Cova de les Rates Penades dentro del LIC/ZEPA «Penyasegats de la Marina». Sin embargo, la presión urbanística u otras actividades humanas, sin descartar los procesos erosivos de origen natural (acción del oleaje, desplomes, entre otros), pueden determinar su degradación; de ahí que sea precisa una mayor puesta en valor y su protección.

\section{La biodiversidad en una costa altamente transformada.}

Una elevada variedad litológica y geomorfológica determinan una gran diversidad de especies vegetales y de fauna. Esta es una afirmación lógica que se puede aplicar para caracterizar la costa alicantina. Pero la elevada ocupación de este territorio, sobre todo a partir de la década de los años setenta del siglo pasado, ha supuesto una reducción notable de dicha biodiversidad que hoy en día pocas investigaciones han estimado (Marco et al, 2012). Aún así, quedan reductos de gran importancia que merecen ser protegidos y conservados. Un estudio de detalle a este respecto supone el desarrollo de un proyecto de gran envergadura; por lo que en este artículo nos limitaremos a destacar aquellos aspectos más relevantes desde el punto de vista de hábitats de interés (Directiva 92/43/CEE), UICN ${ }^{12}$, y catálogos y listas de especies raras, endémicas o amenazadas.

Como ya se ha indicado en el párrafo anterior, este espacio constituye en sí mismo un ecótopo singular, en el que los rasgos litológicos, geológicos, geomorfológicos y las formaciones superficiales, así como su proximidad al mar, desde el punto microclimático, tienen mayor peso en la colonización vegetal y en la fauna asociada que condiciones climáticas más generales. Éste es precisamente uno de los valores para su conservación y protección: su singularidad geográfica; a lo que hay que añadir que al tratarse de un espacio tan humanizado, ocupado y transformado, con un elevado número de endemismos, surgen más justificaciones: la fragilidad y vulnerabilidad de estos ecosistemas.

12. UICN, Unión Internacional para la Conservación de la Naturaleza. Autoridad mundial que establece los estándares sobre los que se desarrollan las políticas medioambientales de sus estados miembros, agencias gubernamentales y sociedad civil, basados en el principio de la sostenibilidad y conservación de la biodiversidad. (http://www.iucn.org/es/) 
Figura 3. Figuras de protección internacionales: Unión Europea, en el litoral alicantino

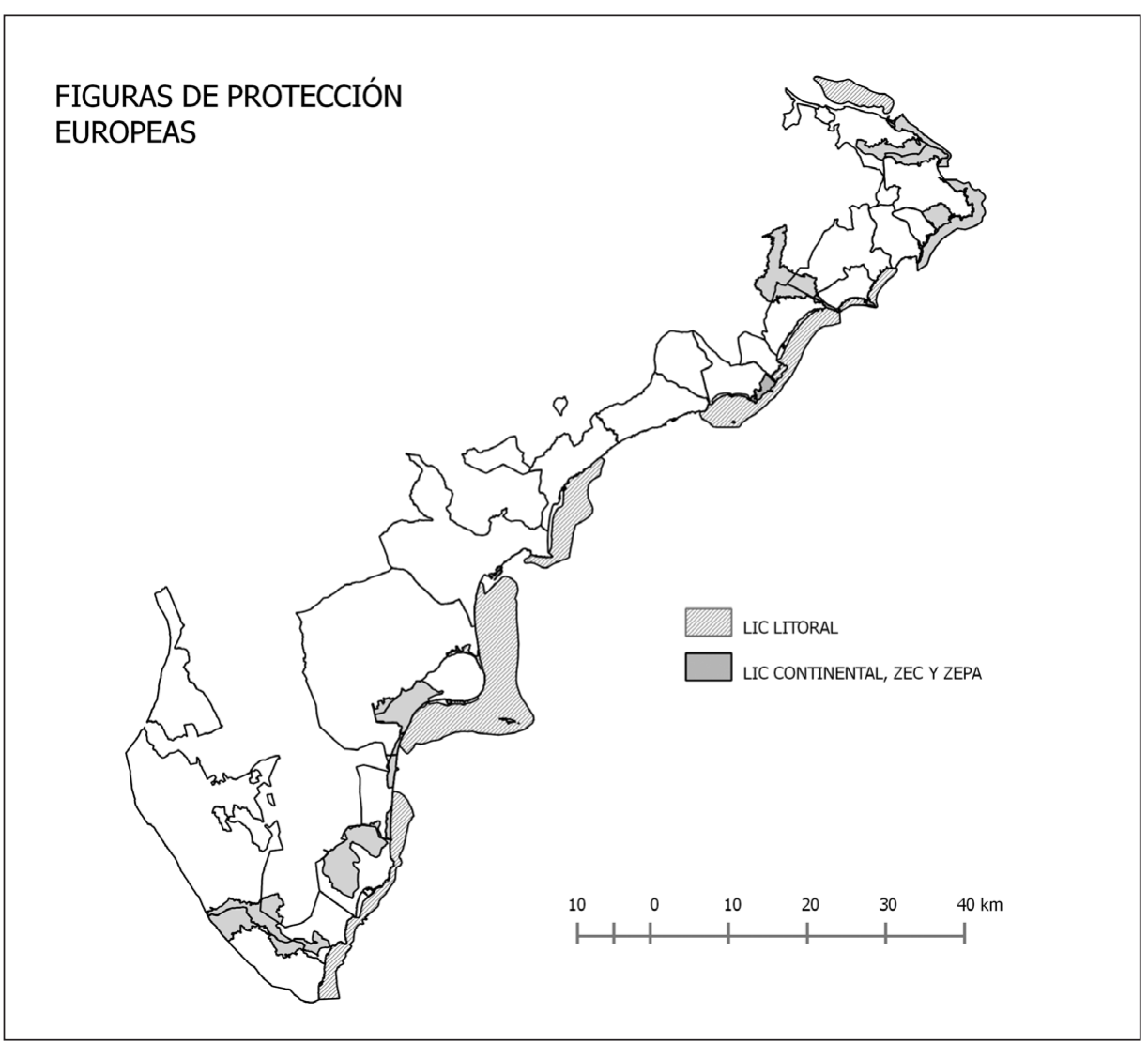

Fte.: Conselleria de Infraestructuras, Territorio y Medio Ambiente. Elaboración propia.

Son numerosos los hábitats de interés establecidos por la Directiva europea (92/43/CEE) en el litoral alicantino, pero de todos ellos, al menos en este trabajo, merecen ser resaltados aquellos considerados como prioritarios por constituir ecosistemas de relevancia internacional, por la singularidad de sus formaciones vegetales o por el contenido en flora y fauna rara, endémica o amenazada que deben ser protegidos con urgencia por su manifiesta fragilidad o probabilidad de desaparición ${ }^{13}$ (Ministerio de Medioambiente, 2005). Entre estos, destacan

13. Los hábitats prioritarios localizados en el litoral alicantino son: 1120-Praderas de Posidonia (Posidonion oceanicae); 1510-Estepas salinas mediterráneas (Limnoletalia); 2250- Dunas litorales con Juniperus ssp; 2270-Dunas litorales con bosques de Pinus pinea y/o Pinus 
las praderas de Posidonia oceanica, especie vegetal de gran importancia para la conservación de la biodiversidad marina (fijación de fondos, oxigenación de las aguas marinas, alimento y refugio para diversas especies) y la protección del litoral, sobre todo de las costas de acumulación (reducción de la fuerza del oleaje y minimización de su impacto en la costa). Pese a ello, los fondos marinos de nuestras costas están protegidos solo parcialmente a través de las figuras de Parques Naturales (Montgó y Serra Gelada) y, abarcando casi la totalidad del hábitat de la Posidonia oceanica, como Lugares de Interés Comunitario (LIC) $)^{14}$ y Zonas de Especial Protección para las Aves (ZEPA) ${ }^{15}$.

Pero para poder afirmar la gran relevancia de la biodiversidad del litoral alicantino, así como de la necesidad de una mayor protección y consideración a la hora de aplicar la ley $2 / 2013$, es preciso indicar aquellos aspectos más destacados. Para ello, seguiremos el esquema de tipos de costa diferenciadas en el apartado anterior: costas de erosión (acantilado tipo plunging, plataforma de abrasión y karst litoral), costas de acumulación (playas de arenas, de cantos) y sectores albufereños.

La elevada endemicidad en las costas de erosión

En el norte de la provincia, desde Les Bovetes hasta la Serra Gelada, con excepción del tramo de Dénia y Altea, predomina una costa acantilada, en general, tipo plunging. En estas zonas, las especies de flora se han de adaptar a la escasez de suelo, aprovechando grietas en la roca e incluso habitando paredes verticales o de gran pendiente. Son ámbitos con muchas dificultades para el desarrollo de la vida vegetal, de ahí el elevado número de endemismos y de flora rara y amenazada.

En concreto, son endémicos de la provincia de Alicante ${ }^{16}$ : Cheirolophus lagunae, Convolvulus valentinus ssp valentinus, Limonium rigualii y L. scopulorum, especies consideradas como «Vulnerables» (UICN), Thymus webbianus como «En peligro» (UICN), Asperula paui ssp dianensis y Sideritis dianica como «Riesgo menor-casi amenazada» (UICN). Esta es una de las justifica-

pinaster; 6110-Prados calcáreos o basófilos de Alysso-Sedion albi; 6220-Zonas subestépicas de gramíneas y anuales de Thero-Brachypodietea.

14. LIC no supone ningún tipo de protección o de conservación hasta que no es declarado por el Tribunal de Justicia del Consejo Europeo como Zona de Especial Conservación (ZEC); es entonces cuando rige ya la obligación de que se desarrollen las medidas de conservación especiales por parte de los países donde se localizan.

15. ZEPAs de espacios marinos del Montgó, de la Marina Alta, de Penyal d'Ifach, de Serra Gelada i litoral de la Marina Baixa, dels Ilots de Benidorm, del Cabo de les Hortes, de Tabarca, de Tabarca-Cabo de Palos y de Cabo Roig.

16. La información relacionada con la flora y fauna rara, endémica o amenazada de este artículo ha sido extraída del Banco de Datos de la Biodiversidad de la Generalitat Valenciana, de Laguna et al (1998), de Mateo y Crespo (2003) y de Serra (2007). 
ciones de mayor peso para proteger y conservar el litoral alicantino: áreas de distribución de especies que superan en muchos casos la franja considerada por la Ley $2 / 2013$.

Por otra parte, también son de interés aquellos endemismos cuya área de distribución se extiende a áreas limítrofes, geográficas o biogeográficas, con la Comunidad Valenciana: Carduncellus dianus, Diplotaxis ibicensis, Medicago citrina y Silene hifacensis. Todas ellas son especies consideradas «Vulnerables», «En Peligro» o «En Peligro crítico» por la UICN, o de interés por la Directiva Hábitat, aparte de estar recogidas en catálogos o listados tanto nacional como autonómico.

No siempre un área de distribución amplia es equivalente a un nivel de amenaza leve; puesto que un aislamiento geográfico de las poblaciones debido a la ocupación y alteración del hábitat potencial por actividades humanas pueden suponer el envejecimiento genético y la reducción de la fertilidad de los ejemplares. Este es el caso de Asplenium marinum. Muchas veces, las consecuencias de una perturbación en el medio, no solo son directas, sino también indirectas, como también sucede con Biscutella rosularis o Urginea undulata ssp caeculi que en las últimas décadas han sufrido el fuerte impacto de la expansión urbanística en las poblaciones más cercanas al mar.

Por contra, puede darse la circunstancia de alguna especie vegetal que, aunque su área de distribución es amplia y con poblaciones de numerosos ejemplares, en el territorio valenciano es rara puesto que se localiza de manera muy puntual: Barlia robertiana, Genista lucida, y Thymbra capitata. Por este motivo, a nivel nacional, europeo o internacional no están protegidas ni recogidas en catálogos, pero sí lo están en el Catálogo Valenciano de Especies de Flora Amenazadas. No es el caso de: Asplenium marinum, citada solo en la Cova del Llop Marí (Xàbia, Alicante) de toda la Comunidad Valenciana y de Helianthemum caput-felis, por la rápida reducción de su hábitat causada por la urbanización de la costa alicantina (Marco et al, 2006). Estas tres especies vegetales, pero fundamentalmente la última, son consideradas de una elevada vulnerabilidad a todos los niveles de protección y conservación.

En este sector septentrional de la costa alicantina las amenazas, como ya se ha ido indicando, están relacionadas con la expansión urbanística y la actividad turística casi a pie de cantil, el desarrollo de infraestructuras y equipamientos o la «sobrefrecuentación» humana, que han determinado la desaparición total de poblaciones, de manera directa o indirecta, y la consiguiente fragmentación de sus hábitats, aislamiento genético y envejecimiento de los ejemplares que las hace más vulnerables a plagas (cochinilla afecta severamente a Medicago citrina) y a los largos periodos de sequía de los últimos años. De manera más puntual, el origen puede ser natural, como los desplomes en los acantilados margosos (Diplotaxis ibicensis, Helianthemum caput-felis, Cheirolophus 
lagunae) o hibridación con sus congéneres (Thymbra capitata con T. vulgaris; Cheirolophus lagunae con Ch. intybaceus que puede llegar a desplazarla ecológica y genéticamente si se incrementa la antropización del litoral).

En las zonas acantiladas al sur de la Serra Gelada, de inferior altura que las del norte, encontramos una serie de endemismos de gran interés, algunos de los cuales ya han sido citados, como es la jarilla cabeza de gato o Helianthemum caput-felis que se localiza puntualmente también en Moraira, pero fundamentalmente en el sur, en el litoral de Torrevieja y Orihuela (Marco et al, 2006 y 2011). Caso interesante es el de Limonium furfuraceum que, aunque no recogido en ningún catálogo, ni considerado con amenaza por la UICN, debería de serlo en la Comunidad Valenciana, ya que su área de distribución es reducida y su hábitat puede ser fácilmente alterado; a pesar de que es abundante en cuanto a número de ejemplares. Caso similar es el de Limonium caesium y Thymus hyemalis.

Los taxones vegetales considerados como «especies vigiladas»o «protegida no catalogada» en el Catálogo Valenciano de Flora de Especies Amenazadas son Cachrys sicula, Erophaca baetica ssp baetica, Senecio auricula y Sideritis murgetana. Se trata del mismo caso que el indicado en el párrafo anterior, con la salvedad de que están recogidos en el Catálogo Valenciano de Especies de Flora Amenazadas con posibilidad de incrementar su categoría debido a la reducción de su área de distribución en la Comunidad Valenciana. Lo mismo sucede con Helianthemum viscarium, con la salvedad de que según la UICN es una especie «Vulnerable».

Se ha considerado interesante incluir en este trabajo a Clematis cirrhosa, que si bien no habita estrictamente sectores costeros, sí que se ubica en barrancos abiertos al mar y, para el caso concreto de la Comunidad Valenciana, solo se ha citado en la Serra de Santa Pola. La amenaza para esta especie reside en los escombros de actuaciones urbanísticas que se puedan verter ilegalmente a los barrancos.

En general, podemos afirmar que el nivel de endemicidad en las costas acantiladas del litoral sur alicantino, es mucho menor comparado con el del norte y por lo tanto, el peligro de desaparición de especies y de pérdida de biodiversidad es menor. Aún así, no hay que olvidar que gran parte de los hábitats de estas especies han desaparecido en esas zonas por la actuación urbanística ligada al turismo en las últimas décadas, aunque no se pueda cuantificar cuanto.

Si bien la endemicidad es elevada en las especies vegetales, por lo que respecta a la fauna no lo es tanto. El grupo reconocido en los espacios protegidos que jalonan el litoral, es el de las aves cuyo hábitat no se circunscribe a la costa sino que es más amplio. Destacan por su categoría de amenaza y por su estado legal: Aquila fasciata (En Peligro-UICN) y Charadius alexandrinus (Vulnerable-UICN). En general, toda la avifauna de estos ámbitos está amenazada por las transformaciones del hábitat (urbanización, infraestructuras, 
etc) que han reducido las formaciones vegetales arbóreas y arbustivas donde se localiza su alimento.

En el sur del litoral alicantino, en concreto en Pilar de la Horadada (Paraje Natural Río Seco) y Orihuela (barranco de La Cañada de la Estaca y alrededores), se han localizado poblaciones del gastrópodo Turodella falcata que, si bien su área de distribución es el Mediterráneo occidental, en la Península Ibérica se reduce al litoral de Motril (Granada) y a estos puntos de la costa alicantina donde la presión urbanística ha provocado su práctica extinción, quedando reducida a la microrreserva de «La Cañada de la Estaca».

\section{La fragilidad de los ambientes psammófilos}

La ocupación, transformación y urbanización de las playas de acumulación desde los años setenta del siglo pasado han degradado considerablemente un medio muy frágil desde el punto de vista geomorfológico y biológico. La especie más característica de las playas de cantos y gravas es el Glaucium flavum, sin existencia de endemismos; mientras que en las de arena, en aquellos casos donde la presión urbanística no ha ocupado el cordón dunar, se puede llegar a distinguir una sucesión catenal según la mayor o menor incidencia de la salinidad atmosférica, movilidad del sustrato y proximidad del nivel freático a la superficie, por lo que la diversidad de ambientes es mucho mayor, así como de flora rara, endémica o amenazada.

Playas de arena en buen estado de conservación son escasas (Roselló, 1979) y se debe a que están protegidas por alguna figura legal, caso de Arenals del Sol (Paraje Natural Municipal), Platja del Carabassí (LIC, ZEPA, Paraje Natural Municipal) y Dunas de Guardamar (LIC y microrreservas: Dunas de Guardamar, Dunes de la Marina y Dunes del Pinet). En estos espacios podemos encontrar especies de interés, sobre todo en las Dunas de Guardamar, donde destaca Linaria arabiniana y Othantus maritimus. Otro sector de interés se localiza en el litoral de Orihuela y Pilar de la Horadada, donde sin embargo, el desarrollo urbanístico ha ocupado parte de este hábitat; aún así, es de destacar la presencia de Helianthemum almeriense ssp scopulorum y de Helianthemum marminorense, especies raras en la Comunidad Valenciana y que, por lo tanto, deberían de llevarse a cabo medidas para su conservación.

En este apartado, hemos incluido las dunas fósiles de la Serra Gelada, puesto que sobre su sustrato arenoso se desarrollan especies de gran interés, como Corema album que de distribución más amplia solo se localiza en este hábitat de toda la Comunidad Valenciana y Sideritis chamaedryfolia ssp littoralis, endemismo exclusivo. De esta segunda especie vegetal, llama la atención que no tenga ninguna categoría de amenaza en la UICN, teniendo en cuenta lo restringido de su área de distribución y que aunque se localiza en un espacio 
protegido, estas dunas tienen un elevado estado de degradación y eutrofización debido a los vertidos de la depuradora de Benidorm, aparte de los proyectos de sujeción del acantilado arenoso debido al riesgo de colapso; dos afecciones que pueden poner en peligro a estas poblaciones.

Especie de gran relevancia y que en la Comunidad Valenciana está en evidente peligro de desaparición es Juniperus oxycedrus ssp macrocarpa. En concreto, en Alicante se localiza en Cova Tallada, Cap Prim, Cap Negre, Serra Gelada, playa de la Barraca-El Portichol y Cala de la Barra; alguna de estas poblaciones, probablemente la de Xàbia, puede estar fragmentada por el desarrollo urbanístico o las infraestructuras.

Por lo que respecta a la fauna, dos son las especies de gran interés en los ambientes sabulícolas alicantinos: Xerosecta explanata (Vulnerable-UICN), gastrópodo del Mediterráneo occidental pero localizado únicamente en Dènia, y Paratriodonta alicantina (En Peligro-UICN) coleóptero de la región de Alicante y de Murcia que, además de zonas del interior, lo podemos encontrar en Arenales del Sol, y Playa del Pinet, municipio de Elche, en Bigastro, en Torrelamata y Guardamar del Segura. El desarrollo turístico ha determinado una clara regresión de la población en el primer caso llegando a su práctica desaparición; mientras que en el segundo ha determinado la fragmentación de su hábitat y su aislamiento genético, también ocasionado por el uso de plaguicidas e insecticidas en la costa.

Intenso aprovechamiento de las zonas húmedas

La provincia de Alicante se caracteriza por el elevado número de espacios húmedos en el litoral, la mayoría de ellos protegidos por diversas figuras de ámbito internacional (RAMSAR), europeo (LIC, ZEC y ZEPA), nacional (IBAS o Areas Importantes para las Aves) y de la Comunidad Valenciana (Parque Natural, Paraje Natural Municipal, Microrreservas de flora y Catálogo de Zonas Húmedas) (Figuras 2 y 3). La causa es doble, por un parte se localiza uno de los hábitats prioritarios de la Directiva 92/43/CEE, 1510-»Estepas salinas mediterráneas (Limonietalia)», y por otra, son zonas muy importantes, con carácter internacional, para las aves migratorias, como puntos de avituallamiento y/o de nidificación.

Las zonas húmedas en la provincia de Alicante están sometidas a la misma presión urbanística que los otros tipos de costa, pero además, han sido explotadas, incluso desecadas, para el aprovechamiento agrícola (fundamentalmente arrozales), obtención de sal y de barilla. Algunos de estos usos se mantienen en la actualidad, como sucede en la Marjal de Pego-Oliva (arroz) y en las Salinas de Santa Pola y en las de Torrevieja y La Mata (sal); en otras se han abandonado, caso de les Salines de Calp o el Saladar d'Aigua Amarga. 
El género de especies vegetales de mayor interés se corresponde con el hábitat prioritario de la Directiva 92/43/CEE, Limonium. Son varias las especies de este grupo que podemos encontrar en el litoral alicantino, como por ejemplo Limonium angustebracteatum, L.cossonianum, L. delicatulum, L. supinum, $L$. thinense aunque destaca el endemismo alicantino L. santapolense.

La mayor riqueza de los espacios húmedos reside en las aves, de ahí que tengan un reconocimiento internacional como zonas RAMSAR, ZEPA o IBAS. El listado de las especies de avifauna es muy extenso, por lo que no ha sido incluido en esta publicación, pero destacan por su elevada amenaza: Aythya nyroca (En Peligro Crítico-UICN), Circus pygargus, Laurus audouinii, L. genei (Vulnerable-UICN), Sterna hirundo y S. sandvicens (Casi Amenazada-UICN). Las amenazas que afectan a las aves acuáticas y que están relacionadas con la ocupación o presión urbanística son la desecación o fluctuaciones del nivel de agua en los humedales, su contaminación y consiguiente deterioro de la vegetación donde nidifican, atropellos en carreteras, colisión con tendidos eléctricos y la propia presencia humana que limita la cría por «sobrefrecuentación» o por contaminación acústica.

Por último, cabe destacar la presencia de dos peces que están en grave peligro de extinción, reconocido no solo por la UICN, sino también a nivel europeo, nacional y autonómico: fartet o Aphanius iberus y samaruc o Valencia hispanica. Tal es su importancia que la Generalitat Valenciana desarrolla un proyecto de recuperación para cada especie dentro del programa LIFE-Natura. Su pervivencia está vinculada a las zonas húmedas con figuras de protección; de no ser así, en la actualidad ambas estarían extintas. La problemática reside en el aterramiento de estos espacios, la contaminación de las aguas, presencia de vertidos, alteraciones del nivel freático, entre otras; impactos a los que hay que añadir la competencia con especies alóctonas que han sido introducidas como la perca americana, la perca sol, la gambusia, que han determinado la reducción notable del fartet y del samaruc, por predación directa o por competencia de los recursos.

Por lo tanto, tras la evidente vulnerabilidad de los hábitats de interés del litoral alicantino, se hace necesario un estudio más detallado de la distribución o corología de estas especies y de su relación con el medio que ocupan, considerando a la litología y geomorfología litoral como otro elemento más a tener en cuenta y a proteger. Igualmente, es urgente realizar la evaluación y valoración del estado actual de todos estos aspectos con el fin de que sean argumento y prueba determinante para ser considerados en el DMPT. 


\section{CONCLUSIONES PRELIMINARES}

De los argumentos y evidencias aportadas con la información presentada en los apartados anteriores se pueden extraer una serie de conclusiones provisionales a falta de la realización de estudios de campo más exhaustivos para estimar mejor la incidencia de la nueva legislación de costas en la protección del litoral alicantino. No obstante su carácter provisional, estas conclusiones generales que a continuación se exponen pueden servir para orientar mejor las futuras investigaciones a emprender.

Precisamente, la principal valoración que cabe hacer respecto a la incidencia de la última modificación de la legislación de costas es la de destacar las negativas consecuencias que de los cambios introducidos por la Ley 2/2013 se derivarán para la conservación de los valores ambientales del litoral español, al detraer parte de los bienes que hasta su entrada en vigor se integraban en el DPMT. Sin duda, este hecho acentuará aún más la ya comentada insuficiencia que deparaba la estrecha franja representada por el DPMT para la protección del litoral.

Por la misma razón y, en particular, por excluir del DPMT parte de los elementos que constituyen los ecosistemas característicos del sistema litoral, su incidencia resultará especialmente grave en el litoral alicantino, cuya configuración litológica, geológica y geomorfológica fundamenta una notable riqueza natural con la presencia de un variado número de especies de vegetación y fauna, en virtud de cuyo valor, muchos de esos espacios han sido objeto de protección a través de su declaración con distintas figuras legales que incluso se solapan en bastantes ocasiones.

El peligro o amenaza que, se prevé, tendrá la aplicación de la actual legislación en materia de costas en el litoral alicantino, hace más urgente reforzar la protección del medio litoral, en el que recaen las competencias de las tres administraciones territoriales ya que, tal como se ha expuesto, sigue siendo claramente insuficiente. Por este motivo, se hace necesario contar con instrumentos de protección y gestión más efectivos, a la par que impulsar la declaración de nuevos espacios protegidos y la ampliación de los límites de los existentes de manera que se procure un blindaje más eficaz del litoral ante posibles cambios como los que, por ejemplo, ocasionará la citada reforma de la Ley de Costas favoreciendo una mayor privatización y alteración del mismo.

En atención a lo anterior, resulta asimismo de gran interés examinar la distribución de las especies citadas y el estado en el que se encuentran sus hábitats, en orden tanto a conocer más a fondo la situación en la que se encuentran como a valorar de forma más exacta la incidencia que puede tener la modificación de los deslindes, para lo cual se requerirá emprender estudios a mayor escala para apreciar con más detalle los efectos de tipo cualitativo y cuantitativo. 
Además de sus propios valores geológicos y paisajísticos, dada la importancia que la protección de los hábitats naturales tiene para la conservación de la biodiversidad que representan las especies de flora y fauna, aparte de aplicar la legislación vigente en materia de conservación de la naturaleza, también sería de gran interés desarrollar y aprobar el Plan de Acción Territorial del Litoral. Este plan debería reforzar la protección del frente litoral más allá de la estrecha franja representada por el DPMT garantizando de manera más efectiva a través de la limitación de usos la salvaguarda de los ecosistemas presentes en él a la par que su uso y disfrute público.

En esta línea, tanto la fragilidad e importancia de los ecosistemas propios del litoral como la extrema presión que soportan estos espacios por parte de distintas actividades económicas, conviene que la elaboración del anterior instrumento de ordenación territorial citado asuma los principios que rigen la planificación y gestión integrada de las zonas costeras, atendiendo a la mejor integración y coordinación de todas las políticas, sectores e instancias administrativas que concurren en el mismo.

Ciertamente, en lo que atañe a la incidencia concreta de la reforma de la legislación de costas en el litoral alicantino es necesario hacer estudios más en detalle que, aparte de atender a los nuevos trazados de las líneas de deslinde, tengan en cuenta la afección de otras figuras de protección para, en los casos necesarios, arbitrar las medidas necesarias para su mejor adaptación y, si es preciso, exigir su revisión y modificación en aras de asegurar una protección más efectiva.

\section{REFERENCIAS BIBLIOGRÁFICAS}

Arana García, E. y Navarro Ortega, A. (2013): «La Ley de Protección y Uso Sostenible del Litoral: ¿un giro hacia lo desconocido?», Revista Vasca de Administración Pública n. 97: 21-60.

BARRAGÁN Muñoz, J.M. (2004): Las áreas litorales de España. Del análisis geográfico a la gestión integrada. Barcelona: Ariel.

BarRagán MuÑoz, J.M. y Chica Ruiz, J.A. (2013): «Evaluación de los Ecosistemas litorales del Milenio de España: una herramienta para la sostenibilidad de la zona costera). Eubacteria 31: 9-14.

Brachya V., Juhasz F., Pavasovic A. y Trumbic I. (1994): Guidelines for Integrated Management of Coastal and Marine Areas with Special Reference to the Mediterranean Basin, Split, Croatia, PAP/RAC (MAP-UNEP), pp III+80.

Cendrero Uceda, A., Sánchez-Arcilla Conejo, A. y Zazo Cardeña, C. (2005): «Impactos sobre las zonas costeras», Moreno RodríGuez, J.M. (Dir.): Evaluación Preliminar de los Impactos en España por Efecto del Cambio Climático. Madrid: Ministerio de Medio Ambiente. pp. 469-524.

GARCÍA JiMÉNEZ, A. (2014): «La reducción de la protección de la costa en la Ley 2/2013: revalorización económica del litoral frente a desarrollo sostenible». Actualidad 
Jurídica Ambiental n. ${ }^{\circ}$ 38: 6-19. Disponible en http://www.actualidadjuridicaambiental.com/wp-content/uploads/2014/08/2014_09_02_Garcia-Jimenez_LeyCostas.pdf

García PÉrez, M. (2004): «El deslinde de las costas», Anuario da Facultade de Dereito da Universidade da Coruña, 8: 391-422.

García Pérez, M. y Sanz Larruga, F. J. (2014): «Reflexiones en torno a La Ley 2/2013, de 29 de mayo, de protección y uso sostenible del litoral y de modificación de la Ley 22/1988, de 28 de julio, de costas» en CARro FernándeZ-VAlmayor, J. L., Ferreira Fernández, A.J. y NogueIRA López, A. (Coord.): La nueva regulación de las costas: IX Congreso de la Asociación Española de Profesores de Derecho Administrativo, Santiago de Compostela, 7 y 8 de febrero de 2014. Madrid: Instituto Nacional de Administración Pública, pp.57-146.

Generalitat Valenciana: Banco de Datos de la Biodiversidad, Consellería de Infraestructuras, Territorio y Medio Ambiente: http://bdb.cma.gva.es/

Instituto Geológico y Minero de EsPaña: Base de Datos de Lugares de Interés Geológico. Ministerio de Economía y de Competitividad. Gobierno de España: http://info.igme.es/ielig/

LagunA, E. et al, (Coord) (1998): Flora rara, endémica o amenazada de la Comunitat Valenciana. Conselleria de Medio Ambiente, Generalitat Valenciana.

LOSADA, I. (2008): «El cambio climático en las zonas costeras; previsiones y estrategias de adaptación», Simposio Internacional Evaluación crítica de las previsiones sobre el cambio climático: una perspectiva científica. Fundación Ramón Areces.- Real Academia de Ciencias Madrid

Marco Molina, J.A. y Matarredona Coll, E. (1993): «La configuración física del litoral valenciano», en Martín Mateo, R. y Vera Rebollo, F. (Dir.) El litoral valenciano. Análisis territorial y valoración de su protección, Madrid: Ministerio de Obras Públicas, Transporte y Medio Ambiente. pp. 19-47.

Marco Molina, J.A., Padilla Blanco, A., Sánchez Pardo, A. y Giménez Font, P. (2006): «Helianthemum caput-felis Boiss. entre Punta Prima y Cabo Roig (litoral suralicantino)», en Giménez, P., Marco, J.A., Matarredona, E., Padilla, A. y SÁNCHEZ, A. (Coords): Geografía física y medio ambiente: guía de campo de las XXI Jornadas de Geografía Física, Alacant: Instituto Universitario de GeografíaUniversidad de Alicante, pp. 169-182.

Marco Molina, J.A., Giménez Font, P., Padilla Blanco y Sánchez Pardo, A. (2011): «Crecimiento urbano y conservación de flora amenazada: aplicaciones cartográficas en el caso de «Helianthemum caput-felis» Boiss». Serie geográfica, 17: 125-139.

Marco Molina, J.A., Padilla Blanco, A., Sánchez Pardo, A. y Giménez Font. P. (2012): «Ensayo metodológico para la estimación de la pérdida de hábitat de Helianthemum caput-felis Boiss en la Península Ibérica (1956-2005)», en CuniLl, R., Pèlachs, A., Pérez-Obiol, R. y Soriano, J.M. (Eds) Las zonas de montaña: gestión y biodiversidad, Barcelona: Fundació Catalunya Caixa-Mont Natura Pirineus, pp. 233-237. 
Matarredona Coll, E., Marco Molina, J.A. y Prieto Cerdán, A. (2006): «La configuración física del litoral sur alicantino», en GimÉnez, P., MARCO, J.A. Matarredona, E., Padilla, A. y Sánchez, A. (Coords) Geografía física y medio ambiente: guía de campo de las XXI Jornadas de Geografía Física, Alacant: Instituto Universitario de Geografía-Universidad de Alicante, pp. 35-48.

Mateo, G. y CRespo, M.B. (2003): Manual para la determinación de la flora valenciana. 3. ${ }^{\mathrm{a}}$ ed.Valencia: Moliner.

MenÉndez ReXACH, A. (2014): «La nueva regulación de las costas: un giro hacia el dominio privado marítimo-terrestre», en CARro Fernández-VAlmayor, J. L., Ferreira Fernández, A.J. y Nogueira López, A. (Coord.): La nueva regulación de las costas: IX Congreso de la Asociación Española de Profesores de Derecho Administrativo, Santiago de Compostela, 7 y 8 de febrero de 2014. Madrid: Instituto Nacional de Administración Pública. pp 13-56.

Ministerio De Medio Ambiente (2005): Los tipos de hábitat de interés comunitario de España. Dirección General para la Biodiversidad. Madrid. Fichas tipo: http://www. magrama.gob.es/es/biodiversidad/temas/espacios-protegidos/red-natura-2000/ rn_tip_hab_esp_espana_acceso_fichas.aspx.

Olcina CÁntos, J. y Miró PÉRez, J. (1998): «Influencia de las circulaciones estivales de brisa en el desarrollo de tormentas convectivas», Papeles de Geografía, 28: 109-132.

Padilla Blanco, A. (2002): Protección y conservación de la flora en la comunidad Valenciana, Investigaciones Geográficas, 27: 107-130.

Padilla Blanco, A. y Such Climent, M.P. (2001): «Biodiversidad florística y turismo en el litoral valenciano», RodríGuez, F. (Coord.) Forma y función del territorio en el nuevo siglo, XVII Congreso AGE. Oviedo: Universidad de Oviedo. pp. 188-194.

Ramón Morte, A. y Padilla Blanco, A. (1997): «Planeamiento ambiental a escala de detalle: microrreservas de flora en la Comunidad Valenciana», Investigaciones Geográficas, 17: 117-130.

RosSELló I VERGER, V.M. (1979): «Valoración científica del litoral alicantino», Investigaciones geográficas, 9: 47-54.

SAnjaume Saumell, E. (1985): Las costas valencianas: sedimentología y morfología. Valencia: Universitat de València.

SERra LALiga, L. (2007): Estudio crítico de la flora vascular de la provincia de Alicante: aspectos nomenclaturales, biogeográficos y de conservación. Madrid, CSIC.

Torres Alfosea, F. J. y Olcina Cantos, J. (1997): «Incidencia de los temporales de levante en la ordenación del litoral alicantino», Papeles de geografía, 26:105-132:

Torres Alfosea, F.J. (2002): «Temporales en el litoral español», Ayala Caicedo, F.J. y Olcina Cantos, J. (coord.): Riesgos Naturales. Barcelona: Ariel. pp-1085-1088.

Torres AlfoseA, F.J. (2002): «Algunos apuntes acerca de los motivos para modificar la Ley 22/1988, de Costas», en Olcina Cantos, J. y Rico Amorós, A.M. (Coord.): Libro jubilar en homenaje al profesor Antonio Gil Olcina. San Vicente del Raspeig, Alicante: Instituto Interuniversitario de Geografía, Universidad de Alicante. pp. 1267-1284. 
Tros-DE-IlarduYA FernÁNDEZ, M. (2005): «Temporales marítimos y ordenación del territorio en la provincia de Alicante» Boletín de la Asociación de Geógrafos Españoles, 40: 329-350.

Tros-DE-IllarduYA Fernández, M (2012): «Áreas de riesgo frente a temporal de mar en la provincia de Alicante», Anales de Geografía de la Universidad Complutense vol 32, n. ${ }^{\circ} 1: 181-196$.

Tros-DE-IllarduYA FernándeZ, M (2013): «Temporales marítimos y borrascas atlánticas en la provincia de Alicante: el caso de Benidorm», Estudios Geográficos; vol 74, n. ${ }^{\circ}$ 274: 287-310.

YAnes LuQue, A. y Marzol JAÉn, M. ${ }^{a}$ V. (2009): «Los temporales marinos como episodios de riesgo en Tenerife a través de la prensa (1985-2003)», Revista de la Sociedad Geológica de España, 22 (1-2):95-104. 